\title{
A presença de grupos religiosos conservadores nos espaços públicos da contemporaneidade
}

\author{
Celso Gabatz \\ Faculdades EST, São Leopoldo, Brasil \\ (i) https://orcid.org/0000-0002-2844-1751 \\ gabatz12@hotmail.com
}

\section{Introdução}

O debate acerca do lugar da religião na sociedade brasileira contemporânea vem consolidando a interação e o protagonismo de diversos sujeitos. Essa perspectiva sugere a ampliação do diálogo no qual as instituições religiosas são convidadas a repensar valores, posicionamentos, atitudes (GUERRIERO, 2006). A regulação das sexualidades pelas diretrizes religiosas fundamentalistas, por exemplo, implica na recusa de modelos igualitários de gênero, exacerba a difusão de uma mensagem sexista e emoldura visões estigmatizadas (MACHADO; PICOLO, 2011).

É importante compreender os sentidos da rejeição de políticas inclusivas e das reivindicações por direitos das minorias para perceber 
os dilemas e incoerências que conectam homofobia, convenções e valores sociais e religiosos. As prerrogativas que suscitam o discurso legitimador da homofobia religiosa, que almeja a cura da homossexualidade com sucessivos apelos à conversão acompanhados de exortações teológicas fundamentalistas, revelam uma preocupação em “poder usufruir” da bondade divina e não ser “condenado” (LOURO, 2007).

Os evangélicos neopentecostais, em particular, têm ocupado um lugar de destacada relevância e de grande visibilidade no cenário religioso nos dias atuais. Essa inserção não decorre apenas de um proselitismo bastante incisivo, mas em grande medida pela sua atuação na esfera pública, com destaque para a mídia e a política (EMMERICK, 2013, p. 21-78). São, portanto, atores que contribuem para amplificar as tensões da modernidade e dar à religião um lugar estratégico.

É preciso salientar que os desafios, demandas e possibilidades da contemporaneidade, reforçam a articulação de grupos "conservadores” que embasam as suas ações sublinhadas pelo entendimento de que a modernidade fez emergir a decadência moral, social, cultural e política (MARTELLI, 1995). Essa decadência estaria diretamente ligada a um "liberalismo teológico" dos movimentos de esquerda, à suposta subversão promovida pelo feminismo, ao crescimento da "libertinagem sexual”, à ameaça das facções políticas “comunistas”, ao afrouxamento das autoridades, das leis, da punição a infratores e ao aumento da criminalidade. (SAFFIOTI, 2004).

A atuação dos grupos conservadores faz com que a arena política torne-se um espaço de disputas reforçando a pergunta pelos limites aceitáveis da liberdade religiosa nem sempre associada à plena conformidade dos direitos humanos a todos os grupos sociais (VANEIGEM, 2004). O exercício de direitos envolve as liberdades pessoais 
que, por sua vez, estimulam a perspectiva das obrigações sociais. Estas envolvem o âmbito público, uma vez que é o Estado que deve garantir as condições adequadas e capazes de assegurar que os direitos sejam exercidos de maneira segura e equitativa por todos os seus cidadãos e cidadãs.

\section{Intolerância, fundamentalismo e regulação da(s) sexualidade(s)}

Se, ao longo da história, houve diversos movimentos importantes pela produção de novos valores, por mudanças de mentalidade, influenciando a transformação das instituições e reordenando a vida social (CASTELLS, 2013), contraditoriamente, o ativismo religioso conservador busca a manutenção de condutas, valendo-se da autonomia de comunicação que a sociedade em rede permite.

De acordo com Boaventura de Sousa Santos (2014), para além do uso das redes móveis para coordenar ações, outro componente do processo comunicativo é a construção de um espaço público no espaço urbano. Algo que é perseguido pelos coletivos religiosos, que ocupam postos e lugares simbólicos, conseguindo colocar contingentes substanciais em protestos nas ruas e conquistando a adesão para suas comunidades mesmo de quem não tem filiação religiosa.

A atuação incisiva de lideranças evangélicas para atuar nos espaços decisórios do Estado brasileiro reflete algumas questões importantes para o debate democrático e para os direitos das minorias LGBT (CUNHA; LOPES, 2013). Caberia perguntar acerca da possibilidade de conciliação entre a garantia da laicidade e a defesa e proteção dos direitos humanos e também a efetivação dos direitos fundamentais através da pregação de lideranças evangélicas investidas ou não de 
mandatos parlamentares (BEATY, 2014). As opiniões deveriam influenciar os debates relacionados às políticas públicas e à elaboração legislativa em um Estado laico?

Ao se opor a leis que incidam sobre a discriminação de pessoas em razão da sua orientação sexual ou identidade de gênero, os argumentos utilizados pelos pastores e parlamentares evangélicos são diretamente derivados de sua leitura bíblica e da moral de suas igrejas. Não há uma preocupação em sustentar essas posições em termos laicos ou universalizáveis para o conjunto da população que não compartilha da mesma fé religiosa (MACHADO, 2012).

É salutar aprofundar o debate e compreender com maior perspicácia se argumentos do âmbito pessoal no tocante à moral religiosa deveriam ser considerados de forma tão incisiva para o reconhecimento de direitos em um Estado laico? Cabe observar que a moral de uma sociedade democrática deveria ser crítica e não estar apenas apoiada em determinadas tradições, ainda que majoritárias. Como indicado por Roger Raupp Rios:

A convicção religiosa alheia, não pode, portanto, privar de direitos um grupo social que não se recusa a cumprir os deveres gerais da cidadania. Além de serem livres para crer, os cidadãos brasileiros são livres para não serem privados de direitos por grupos religiosos terem feito leis fundadas em suas convicções religiosas. Dizer, portanto, que não se estendem a certos grupos (como gays e lésbicas) direitos que existem para outros pela "índole religiosa" da maioria ou pelo "direito natural” de caráter revelado ou pseudocientífico [...] é contrariar diretamente o direito constitucional (RIOS, 2011, p. 39).

Interessante perceber que o ideal buscado por algumas lideranças religiosas é a representação do cristão combativo, cuja vida deve ser um testemunho para a sociedade. Este não deveria dobrar-se às tentações do mundo e aos “modismos” da igreja. Algo semelhante à ideia 
desenvolvida por Karen Armstrong sobre a religiosidade fundamentalista como guerreira e combativa que cria uma contracultura não utópica para opor-se à sociedade secular (ARMSTRONG, 2001, p. 917).

É inequívoca a posição assumida no sentido de aceitar, acolher e amar para tentar “corrigir”, “reorientar”, “ajustar”. A proposta é “curar" segundo determinados "valores" e "verdades". Trata-se de uma visão tutelar, de correção moral (FOUCAULT, 1988). Sustentando a ideia de que, assim como o fenômeno da delinquência atenta e prejudica a sociedade, os homossexuais, sendo um fato social, existem, mas precisam ser corrigidos para que não causem dano ou mal à família, aos bons costumes, à ordem religiosa. ${ }^{1}$

A denúncia de uma suposta agenda oculta do movimento pelos direitos civis da população LGBT também é algo a ser combatido. É uma tática que visa dar legitimidade aos argumentos, retratando ideias, princípios e táticas nascidas do protestantismo de extrema direita norte-americano.

Não se engane, a estratégia homossexual é um plano tático para a guerra. Não se trata de uma reunião política pública ou de uma estratégia de marketing: a estratégia que tem sido disseminada pelo lobby homossexual é uma de natureza militar. [...] Esta não é uma batalha contra inimigos estrangeiros, mas contra um inimigo ainda maior: as forças das trevas e legiões de gays e lésbicas furiosas e determinados a abolir a virtude cristã e o julgamento moral de qualquer forma (SHELDON, 2012, p. 267).

1. O Pastor Silas Malafaia, por exemplo, engajou-se pessoalmente na tradução, divulgação e promoção do livro do pastor norte americano Louis Sheldon, denominado The agenda. Traduzido para o português como A estratégia - o plano dos homossexuais para transformar a sociedade. O livro foi vendido no catálogo de uma popular empresa de cosméticos, o que ensejou uma campanha de boicote e denúncia por parte do movimento LGBT. Disponível em: www.cartacapital.com.br. Acesso em: 22 maio 2016. 
Os fundamentos da retórica beligerante evidenciam a caracterização negativa do “estilo de vida” dos homossexuais como algo doentio e na suposta tentativa dos mesmos de instalar uma sociedade submissa aos seus ditames - algo como um verdadeiro "império homossexual”, como denunciou recentemente o senador evangélico Magno Malta (PR-ES), em discurso na tribuna da câmara dos deputados. ${ }^{2}$

A suposta piedade e compreensão amorosa acabam sendo, com efeito, mais estratégias retóricas para a normatização pastoral e sexual. São aludidas de forma contínua e abundante diversas questões inerentes a concepções de gênero, família e sexualidade que acabam não sendo amparadas do ponto de vista do conhecimento científico e também no âmbito da vivência social, dadas as transformações culturais, sociais, jurídicas e históricas das últimas décadas (GIDDENS, 1993).

Importante destacar que, de acordo com Pierre Bourdieu (1998), a religião forneceria justificativas para a existência humana por produzir um sentido para a vida. Mas esse sentido, necessariamente, precisaria estar contextualizado. Isso porque a produção operada na religião só é considerada pela sociedade ao desempenhar um papel significativo e estruturante, aceito ou admitido por determinado grupo.

A religião reveste o social com uma aura sagrada e faz a correspondência entre a ordem social e a ordem simbólica. Esta particularidade lhe outorga uma função política estruturante (BOURDIEU, 1998, p. 33). Na perspectiva de Oro (1996), a realidade contemporânea tem suscitado premissas de cunho fundamentalista também pela decorrência da vulnerabilidade social enquanto efeito da globalização e da modernidade.

Zygmunt Bauman, por sua vez, mostra que "o fascínio do funda-

2. Disponível em: www12.senado.gov.br. Acesso em: 10 jun. 2016. 
mentalismo provém de sua promessa de emancipar os convertidos das agonias da escolha” (1998, p. 228). Segundo o autor, o fundamentalismo tornou-se um remédio radical contra o veneno da sociedade de consumo. É possível afirmar que os indivíduos encontram respostas do que pensar, dizer ou fazer. Seria quase um resgate de valores das tradições ancestrais; algo capaz de fornecer sentido à vida e propiciar uma sensação de controle sobre a incessante chegada do novo (BERGER, 2017).

O discurso com base em algumas diretrizes naturalistas e jurídicas acaba sendo explorado de forma mais enfática (LOREA, 2008). São formulações que incorporam parcela dos princípios dos direitos humanos, realçando ambivalências do ideário dos movimentos sociais (BAJOIT, 2006, p. 251-76) e que motivam itinerários dados pelos “limites” das prerrogativas contidas na proposta de criminalização da homofobia (LEITE, 2014).

O grande desafio que se impõe é o de valorização da autonomia diante do reconhecimento de que os indivíduos não possuem as mesmas condições para acessar e exercer os direitos, pois são condicionados por processos históricos de opressão, discriminação, dominação e exploração, moldados por diversas questões de ordem cultural, étnica e religiosa (LE GOFF, 1995). Compete ao Estado e, portanto, às instituições do Poder Público, a garantia para que todas as pessoas possam exercer livremente seus direitos situados no marco normativo político e conceitual dos direitos humanos (MORI, 1997).

O filósofo e sociólogo alemão, Jürgen Habermas (2007), conhecido pela defesa das teorias da racionalidade comunicativa e da esfera pública, reitera que, na sociedade contemporânea, o Estado regido pelo constitucionalismo democrático deveria garantir a sua sustentação com base na participação simétrica dos indivíduos enquanto 
atores e, ao mesmo tempo, destinatários das leis. Refere que os resultados da participação política deveriam ser aceitáveis pelo conjunto dos cidadãos e cidadãs.

O procedimento democrático extrai sua força geradora da legitimação de dois componentes, a saber: da participação política simétrica dos cidadãos, a qual garante aos destinatários das leis a possibilidade de se entenderem, ao mesmo tempo, como autores; e da dimensão epistemológica de certas formas de uma disputa guiada discursivamente, as quais fundamentam a suposição de que os resultados são aceitáveis em termos racionais. As expectativas e os modos de pensar e de se comportar dos cidadãos, que não podem ser simplesmente impostas mediante o direito, podem ser, no entanto, explicitadas a partir desses dois componentes da legitimação. As condições para uma participação bem-sucedida na prática comum de autodeterminação definem o papel do cidadão no Estado: os cidadãos devem respeitar-se reciprocamente como membros de sua respectiva comunidade política dotados de iguais direitos, apesar de seu dissenso em questões envolvendo convicções religiosas e visões de mundo (HABERMAS, 2007, p. 136).

A inserção dos grupos conservadores na esfera publica reforça a perspectiva de negação do pluralismo. A defesa de uma premissa religiosa de forma unilateral implica em um aviltamento de outras compreensões morais, e, sobretudo, uma transgressão do poder público no princípio de neutralidade do Estado com respeito aos distintos credos, um requisito da democracia (MARTI; GANIEL, 2014, p. 34-56).

O conservadorismo religioso no Brasil tem conseguido atuar politicamente, na maioria das vezes, não como participante ou promotor de um debate entre distintas forças políticas e cidadãs, mas muito mais no sentido de alcançar determinadas demandas arbitrárias ${ }^{3}$ às instituições democráticas. Há uma intervenção aberta através da eleição de

3. A proposta legislativa n ${ }^{\circ} 478 / 2007$, conhecida como Estatuto do nascituro, é um reflexo da persuasão política dos grupos conservadores na Câmara Federal. A proposta incide sobre a vida desde a sua concepção, ao criar deveres ao Estado, à 
representantes em posições legislativas e executivas (COSTA, 2008).

O efetivo exercício de direitos abarca uma transformação da lógica na qual está baseado o sentido das leis. Uma transformação que possibilite um deslocamento da lógica da prescrição e controle para o princípio da ética e da liberdade. As políticas públicas orientadas para as demandas de direitos deveriam estar pautadas com vistas à concretização da justiça social (CORREGIDO, 2004). Nesse sentido, necessitam ser formuladas e executadas levando em conta as desigualdades de gênero, de classe, de raça e de expressão sexual.

A visão propagada pelo conservadorismo religioso reforça o ideal de que o legislativo é um espaço no qual os diferentes grupos vão sendo representados na defesa de seus interesses, mas onde as normas legais serão definidas em função dos sistemas de valores da maioria ali representada que é, no caso brasileiro, cristã. Mesmo que se incorpore no debate parlamentar argumentos de natureza jurídica, psicológica, médica e de outros campos do conhecimento, tais argumentos estarão a serviço da convicção de que a sociedade brasileira não deve alterar as normas legais criadas a partir do modelo heterossexual de família.

família e à sociedade no sentido de garantir a inviolabilidade da vida e proibir o aborto, institucionalizando o controle sobre a vida e os corpos das mulheres. Contradiz os direitos da mãe contemplados no Código Penal ao tratá-los como questão de política criminal, ao invés de entendê-los como problema de saúde pública. Com clara influência religiosa, o estatuto afronta o princípio da laicidade do Estado ao difundir uma determinada concepção religiosa acerca do início da vida, seu valor, a autonomia das mulheres, a liberdade e a igualdade (ANGELIN, 2015, p. 182-98). 


\section{Poder, persuasão e novos domínios da(s) identidades(s)}

As identidades conservadoras ${ }^{4}$ articulam-se no lastro de algumas premissas de restauração de um movimento mítico original, quer seja, a "cristandade”, a “sociedade”, as “comunidades autênticas” ou a “igreja fiel ou heroica” (BEATY, 2014). Também faz alusão à emergência de ditaduras totalitárias que levariam à perseguição e ao martírio dos cristãos, dos "homens e mulheres de bem”. Daqueles e daquelas que "sentem-se chamados" a defender a "verdadeira família" (MALAFAIA, 2012). Uma defesa intransigente com rescaldos de belicosidade.

A articulação de grupos conservadores nas últimas décadas é uma referência imprescindível para compreender os contornos das sensibilidades religiosas contemporâneas na perspectiva dos direitos (CATROGA, 2006). A multiplicação dos espaços de atividades religiosas, o espetáculo das massas, a penetração de agentes religiosos em todos os níveis do Estado, acabou por criar novas demandas em relação à força persuasiva da imagem do Brasil como nação católica, além de

4. Mesmo conhecidos por utilizarem critérios bíblicos, por vezes, literais, para sustentar suas posições, as referências a estes grupos são cada vez mais seculares. É comum o uso de terminologias ligadas ao direito, economia, ciências médicas e biológicas. Percebe-se que não há tanto empenho em argumentar publicamente com base apenas em razões teológicas, mas muito mais a partir de um sentido de preservação moral e dos bons costumes. É um discurso que apela mais para os valores civis e a democracia, ainda que esta seja interpretada de forma bastante particular. A pesquisadora Jaris Mujica refere que: "O ativismo conservador que defende as tradições, [...] penetrou estrategicamente no secular. Isso obriga a pensá-lo de maneira diferente e a repensar a figura do fundamentalismo religioso. É preciso considerar que o olhar que se teve sobre o fundamentalismo criou imagens essenciais desses grupos e evitou o registro de suas práticas e estratégias, gerando estereótipos. Diante dessa situação, o uso da categoria ‘grupos conservadores’ aponta a uma posição compreensiva [...] e permite entender as referidas estratégias práticas à luz das transformações” (MUJICA, 2011, p. 94-5). 
conferir novos instrumentos de poder e de influência na formação da opinião pública, modificando a percepção sobre o que corresponde ao interesse coletivo (SANTOS, 2003).

Cabe ressaltar que a realidade brasileira contemporânea tem repercutido inúmeras situações marcadas pelos dilemas das diferenças. O aparecimento de reivindicações com base na diferença traz à tona uma reflexão e uma disputa, muitas vezes veemente, sobre o lugar, os direitos, as representações, a vez e a voz das minorias. A diferença não pode ser compreendida apenas como conceito filosófico ou semântico (SEMPRINI, 1999, p. 11). A diferença é antes de tudo uma realidade concreta, um processo humano e social que insere os indivíduos em suas práticas cotidianas a partir de um processo histórico. É, pois, necessário pensar, entender, refletir a partir da diferença assumindo uma nova postura.

O indivíduo ou o grupo não são sujeitos quando pairam sobranceiros acima das condutas práticas. O sujeito é mais forte e mais consciente de si mesmo quando se defende contra ataques que ameaçam sua autonomia e sua capacidade de perceber-se para reconhecer-se e ser reconhecido como tal [...]. O sujeito não é apenas aquele que diz eu, mas aquele que tem a consciência de seu direito de dizer eu. É por isso que a história social é dominada pela reivindicação de direitos: direitos cívicos, direitos sociais, direitos culturais, cujo reconhecimento é exigido hoje de maneira tão premente que constituem campo mais delicado no mundo em que vivemos (TOURAINE, 2006, p. 112-13).

A “epistemologia multicultural”"5 traz à tona as contradições da so-

5. Importa destacar que multiculturalismo tem sido empregado para indicar o caráter plural das sociedades ocidentais contemporâneas. Compreende-se enquanto resposta aos desafios impostos à sociedade, à medida que inclui a formulação de definições conflitantes de mundo social, decorrentes de distintos interesses econômicos, políticos e sociais. Em tal formulação, as relações de poder desempenham papel relevante, auxiliando a confrontar a maneira como os indivíduos, grupos e 
ciedade brasileira que tantas vezes se professou universalista e igualitária, ${ }^{6}$ mas que, diante dos questionamentos, descobre-se profundamente marcada pelas desigualdades. Em última instância, o que está em jogo nessa dinâmica é o projeto de uma sociedade construída de acordo com as premissas da globalização e da modernidade. Infelizmente a "análise monocultural [...] garante que a verdade existe e que é possível conhecê-la, que existe uma solução para cada problema e que é a ciência quem dará tal solução” (SEMPRINI, 1999, p. 89).

A consolidação de parâmetros para uma convivência que motive a pensar na perspectiva da inclusão remete para o exercício da compreensão e do respeito mútuo. Se a convivência se encontra centrada na dominação cultural de um grupo ou de uma corrente ideológica, será preciso perceber o multiculturalismo como o caminho para reconhecer a alteridade e o direito à diferença dos grupos que se sentem excluídos do processo social. Ao se defender a existência de uma verdade imposta a toda coletividade, mesmo sabendo que existem direitos absolutos, princípios jurídicos muito relevantes são desconsiderados (EMMERICK, 2013, 278-79). Os direitos somente podem ser garantidos com a proibição de imposições de moralidades religiosas

instituições tencionam consolidar suas identidades. O multiculturalismo questiona a afirmação de que a realidade existe independente do sujeito e da linguagem utilizada. Afirmar que a realidade é uma construção e que está fortemente ligada ao sujeito e à linguagem é uma oposição direta à suposta objetividade científica preconizada na modernidade (MCLAREN, 1997).

6. Gilberto Freyre foi um dos pioneiros do "mito da democracia racial" apregoando que existiria, no Brasil, a igualdade de oportunidades para brancos, negros e mestiços. A disseminação desse mito permitiu esconder desigualdades raciais, que ainda podem ser constatadas nas práticas discriminatórias de acesso ao emprego, nas dificuldades de mobilidade social da população negra e que recebe remuneração inferior à do branco pelo mesmo trabalho e tendo a mesma qualificação profissional. A falta de conflitos étnicos não caracteriza ausência de discriminação, mas este silêncio favorece o "status quo" que, por sua vez, beneficia a classe dominante (FREYRE, 2001). 
hegemônicas.

A forte atuação de grupos religiosos conservadores no parlamento brasileiro busca garantir algumas prerrogativas morais e teológicas na regulação jurídica no tocante aos direitos relacionados a família, sexualidade, reprodução e aborto. O reconhecimento da sexualidade e da reprodução como direito humano ainda é algo bastante recente. Tal fato redunda em uma prevalência do senso comum e de tabus na sociedade em geral.

O crescimento dos movimentos feministas e os ganhos na criação de leis que regulamentam o aborto e a implementação de políticas públicas referidas a direitos sexuais e reprodutivos, ao lado da expansão dos direitos das mulheres indicaram que novos valores se fazem presentes na sociedade contemporânea (MACHADO, 2008, p. 243).

O grande desafio é o de pensar a religião no contexto dos conflitos contemporâneos. Compreender que a cultura e as identidades acabam se articulando de forma estratégica com a democracia, a diversidade e os direitos (BOFF, 2006). A religião acaba sendo parte da emergência de uma cultura e condicionada pelos embates e conflitos decorrentes do pluralismo, da intolerância e da consolidação de políticas democráticas.

A questão não é mais, pelo menos num futuro próximo, se 'a religião’ deve estar presente na esfera das instituições públicas, mas como dar sentido a esta presença, como perceber suas diferentes modalidades, impactos e fontes e como avaliar as distintas implicações das relações entre esses atores (e mesmo projetos) religiosos e seus interlocutores e adversários não religiosos (BURITY, 2008, p. 93).

É preciso sublinhar que a reconfiguração da democracia no Brasil, ainda que de forma incipiente, produziu avanços e gerou modificações importantes no âmbito das estruturas políticas. Houve mobili- 
zação e abertura para que surgissem novos agentes. Nesse contexto, foram sendo demarcados fluxos, instaurados intercâmbios e ampliados domínios. Foram surgindo vozes que estenderam a repercussão de temas concernentes à diversidade de gênero, sexual, cultural, ética e, também, souberam repercutir as demandas pela garantia de políticas de convivência e alteridade, consolidação de direitos e tolerância (SORJ, 2001).

As mudanças ocorridas no âmbito do processo político brasileiro com modificações nas estruturas do Estado induzindo para uma relativa descentralização dos capitais, a expansão da democracia e dos direitos humanos forçou os grupos conservadores a construir um discurso público tendo como premissa os ideais em torno da defesa da vida. Houve uma mudança estratégica de ação e discurso que tem consolidado:

A participação de novos atores políticos [...]. Um interesse dos meios de comunicação no tema dos direitos, exclusão, democracia, justiça em que as formas clássicas de exclusão [...], apesar de ser uma prática que não foi eliminada dos imaginários e das relações sociais, já não são legitimados pelos discursos políticos. Produz-se uma fenda na correlação entre as elites, isto é, entre o controle dos grupos conservadores e o Estado. [...] Novos atores, novos processos e um sistema diferente, diante do qual tem de elaborar novas maneiras de penetração e controle (MUJICA, 2011, p. 91).

Há uma efetiva preocupação não apenas em relação ao discurso, mas, sobretudo, com estratégias práticas e ações efetivas nos espaços de interação social (HERVIEU-LÉGER, 2008). Dessa maneira, o que ocorre é uma permanente e obstinada busca por influir no espaço público visando consolidar determinadas leis, subjugar políticas públicas de inclusão das minorias, criticar materiais educacionais produzidos pelo Estado de modo a garantir e ampliar o horizonte dos direitos constitucionais. 
Em suma, os grupos conservadores se transformaram. Reconstruíram-se politicamente em uma reação diante da secularização. No entanto, esta transformação não foi única. Esses grupos têm [...] reconstruindo seus discursos e seus conceitos para se adaptarem às mudanças políticas e econômicas nos últimos séculos [...]. A inserção na política partidária, nas direções, nos movimentos político-sociais de base mostra que são grupos dinâmicos, diferentes das sociedades herméticas que se têm imaginado regularmente. $\mathrm{O}$ ativismo conservador inseriu-se no debate da democracia formal utilizando seus procedimentos. Nessa inserção formou agrupamentos laicos e aprendeu a ser estrategicamente secular. $O$ assunto é que é preciso reconhecer que o ativismo conservador também é parte da democracia, de seus procedimentos e de seus mecanismos de demanda (MUJICA, 2011, p. 95-6).

Essa adequação contextual dos grupos conservadores traz à tona um deslocamento dentro da sociedade civil organizada. Consolida-se uma agenda de trabalho e de incidência pública através de grupos profissionais especializados e de forças políticas que embora não se valham explicitamente das referências do conservadorismo religioso, manifestam-se contrários a temas como os relacionados aos direitos sexuais e reprodutivos. ${ }^{7}$

A defesa da vida aparece como uma estratégia política e discursiva moralmente efetiva, mas tem problemas quando se aproxima da prática concreta das pessoas. Não pode superar o problema da mortalidade materna, os problemas de debate sobre a vida digna, a demanda no uso de contraceptivos, a tendência à descriminalização do aborto (MUJICA, 2011, p. 98).

A percepção e a magnitude do ativismo conservador por parte da-

7. É comum a superação da formalidade partidária ou da dicotomia ideológica entre direita e esquerda. Os partidos não determinam as demandas conservadoras e nem delimitam temas. Os grupos conservadores têm ampliado sua estratégica através da criação de associações formadas por profissionais especializados, como, por exemplo, de médicos, engenheiros, profissionais liberais, professores universitários e advogados. Disponível em: www.anajure.org.br. Acesso em: 12 jun. 2016. 
queles e daquelas que lutam em favor dos direitos sexuais e reprodutivos se deve, em grande medida, pelo fato de que são atores que ocupam vários espaços de maneira individual, em situações estratégicas de decisão política, mas também pela expressiva utilização dos espaços da tecnologia virtual, maximizando pautas.

Sinteticamente, o que se percebe é que [...] tem como objetivo principal combater as ações [...] que visam avançar na garantia dos direitos sexuais e reprodutivos, bem como barrar toda e qualquer ação ou projeto de lei que afronte os princípios morais e religiosos sobre a vida e a família. [...] tem posicionamentos divergentes no que diz respeito aos mais diferentes temas, mas, em relação às temáticas relacionadas ao aborto, tem um posicionamento convergente, ou seja, se opõem a toda e qualquer ação que vise descriminalizar ou aumentar os permissivos legais do aborto, por considerar que a vida inicia-se no momento da concepção (EMMERICK, 2013, p. 214-15).

Portanto, a inserção de grupos religiosos conservadores no espaço público brasileiro tem sido acentuada em decorrência da reconfiguração de algumas premissas teológicas, pela militância incisiva, pelo engajamento e afirmação de espaços deliberativos e estratégicos em uma contínua elaboração de discursos pautados na defesa da "moralidade” e da "vida”. Talvez a grande disputa na construção dos direitos no espaço público brasileiro nem seja a reafirmação da neutralidade das instituições republicanas, mas a constituição de meios adequados para incorporar os conflitos inerentes às lógicas culturais e religiosas nos debates públicos (ROSADO-NUNES, 2008, p. 67-81).

Essa "guerra santa" contra o reconhecimento dos direitos das minorias tem muito a ver com os direitos de reconhecimento, nos termos de Nancy Fraser (2001) e com a noção de justiça social, pois se trata de erradicar conceitos relacionados aos grupos sociais historicamente discriminados. Ou seja, não basta perseguir a igualdade de renda ou garantir políticas sociais (os direitos de redistribuição): é também pre- 
ciso enfrentar preconceitos e promover positivamente determinadas populações em um processo de valorização cultural e combate a estigmas (GOFFMANN, 1989). Um ideal antagônico à crença e à prática de lideranças conservadoras.

Em certa medida, líderes religiosos têm o direito de expressar as posições da forma como considerarem adequado. A dificuldade surge quando se defende uma visão conservadora confundindo liberdade religiosa e de expressão com uma espécie de guerra contra a diversidade (MARTI; GANIEL, 2014, p. 162-75). São ações que alimentam a intolerância, monopolizam uma determinada "verdade” e abrem as portas para uma religiosidade eivada de ódio e repleta de incompreensões.

\section{Considerações finais}

No Brasil, nos últimos anos, vive-se um momento de redefinição e reformulação da agenda de direitos humanos, em que são incorporados temas como os direitos econômicos, sociais e culturais, ao lado dos tradicionais direitos civis e políticos. Nesse cenário, com base nos parâmetros internacionais e constitucionais, é imprescindível atentar para extremismos religiosos que subjugam a tolerância, limitam o diálogo e descaracterizam o mútuo aprendizado entre os diversos protagonistas que articulam o debate (BATISTA e JÁCOME, 2014).

O argumento da "liberdade de crença” oculta estratégias insidiosas de construção da superioridade moral da heterossexualidade e desqualifica a diversidade sexual, na maioria das vezes colocando-a no âmbito dos desvios, das patologias, das aberrações (NATIVIDADE, 2006). A homofobia religiosa se expressa na reprodução de estereótipos que desqualificam a diversidade sexual realçando o seu caráter "pecaminoso”, "hostil” e “perigoso”. 
Importante observar que, sob a perspectiva sociológica, essa relação acentua a produção de assimetrias sociais, desigualdades de oportunidades, diferenças de status, obstrução de direitos, estereótipos negativos. O conservadorismo e a intolerância religiosa fortalecem-se quando operam discursos baseados em valores que realçam táticas plurais de desqualificação e controle (LUCKMANN, 2014). Essa retórica não se manifesta somente nas percepções e juízos morais, mas envolve formas de atuação em oposição à visibilidade e reconhecimento de minorias, tanto na esfera pública como na privada.

As controvérsias suscitadas chamam a atenção para o papel do Estado e para o ativismo político de grupos religiosos na configuração do campo religioso brasileiro, no reconhecimento público das diferentes organizações religiosas, na regulação da ocupação religiosa de espaços públicos e na concessão de benefícios (FISCHMANN, 2008). Também, lança luz à existência de múltiplos sentidos da laicidade em um país que permite aos seus muitos agentes a luta por demarcar, subjugar e manipular a laicidade do Estado através de muitas fronteiras (LEITE, 2014).

É preciso reconhecer que um mercado religioso, como no caso brasileiro, tem impactado no recrudescimento das disputas religiosas que opõem denominações com desdobramentos na esfera pública, especialmente na arena política e na mídia eletrônica. A prerrogativa constitucional apesar de balizar a atuação política de grupos religiosos, ao que parece, não dispõe ainda de grandes artifícios jurídicos ou políticos para auxiliar nos processos de consolidação da diversidade (FONSECA, 2013).

A atuação de atores religiosos no espaço público em relação a temas controversos do ponto de vista da moralidade religiosa tem sido paradoxal e ambígua. Numa sociedade diversa, multicultural e demo- 
crática como a brasileira, a participação de diferentes grupos na consolidação de políticas públicas e na regulação jurídica pode ser legítima e positiva, desde que sejam estabelecidas regras nas quais os argumentos religiosos sejam traduzidos para o âmbito constitucional de modo a orientar a defesa e a preservação dos direitos humanos (SARMENTO, 2006).

Para não ser subjugado pela retórica do preconceito e a violência simbólica, é necessário exercitar a crítica pública. É com ela que talvez seja possível encontrar caminhos para vivenciar a alteridade, a consciência de direitos humanos, a tolerância, o entendimento e a convivência mais fraterna em uma esfera pública ainda muito refratária ao preconceito.

\section{Referências}

ANAJURE. Associação Nacional de Juristas Evangélicos. Disponível em: www.anajure.org.br. Acesso em: 12 jun. 2016.

ANGELIN, Rosângela. Direitos sexuais e direitos reprodutivos das mulheres: avanços e desafios na construção da democracia. Coisas do Gênero. Revista de Estudos Feministas em Teologia e Religião (EST). v. 1 n. 2. p. 18298, dez. 2015.

ARMSTRONG, Karen. Em nome de Deus - o fundamentalismo no Judaísmo, no Cristianismo e no Islamismo. São Paulo: Companhia da Letras, 2001.

BAJOIT, Guy. Tudo muda. Proposta teórica e análise da mudança sociocultural nas sociedades ocidentais contemporâneas. Ijuí: UNIJUI, 2006.

BATISTA, Carla Gisele; JÁCOME, Márcia Laranjeira. Conservadorismo no Brasil: modos de atuação e estratégias ofensivas aos direitos sexuais e direitos reprodutivos. In: OROZCO, Yury Puello. (Org.) A presença das mulheres nos espaços de poder e decisão. São Paulo: Católicas pelo Direito de Decidir, 2014. p. 93-102.

BAUMAN, Zigmunt. O mal-estar da pós-modernidade. Rio de Janeiro: 
Zahar, 1998.

BEATY, David M. A essência do Estado de Direito. São Paulo, Martins Fontes, 2014.

BERGER, Peter L. Os múltiplos altares da modernidade: rumo a um paradigma da religião numa época pluralista. Petrópolis: Vozes, 2017.

BOFF, Leonardo. Virtudes para um outro mundo possível. Convivência, respeito e tolerância. Petrópolis, Vozes, 2006.

BOURDIEU, Pierre. A economia das trocas simbólicas. São Paulo, Perspectiva: 1998.

BURITY, Joanildo A. Religião, política e cultura. Tempo Social (Revista de Sociologia da USP), v. 20, n. 2. p. 83-113. 2008.

CASTELLS, Manuel. Redes de indignação e esperança: movimentos sociais na era da internet. São Paulo: Zahar, 2013.

CATROGA, Fernando. Entre deuses e césares: secularização, laicidade e religião civil. Coimbra: Almedina, 2006.

CORREGIDO, Maria Dolores Juliano. Excluídas y marginales. Madrid: Cátedra Instituto de La Mujer, 2004.

COSTA, Maria Emília Corrêa da. Apontamentos sobre a liberdade religiosa e a formação do Estado Laico. In: LOREA, Roberto Arriada (Org.). Em defesa das Liberdades Laicas. Porto Alegre: Livraria do Advogado, 2008. p. 97116.

CUNHA, Christina Vital; LOPES, Paulo Victor Leite. Religião e política: uma análise da atuação de parlamentares evangélicos sobre direitos das mulheres e de LGBTs no Brasil. Rio de Janeiro: Fundação Heinrich Böll, 2013.

EMMERICK, Rulian. Religião e direitos reprodutivos. O aborto como campo de disputa política e religiosa. Rio de Janeiro: Lumen Juris, 2013.

FISCHMANN, Roseli. Estado Laico. São Paulo: Memorial da América Latina, 2008.

FONSECA, Francisco Tomazoli da. Religião e Direito no Século XXI: a liberdade religiosa no Estado Laico. Curitiba: Juruá, 2013.

FOUCAULT, Michael. História da sexualidade I: a vontade de saber. Rio de Janeiro: Edições Graal, 1988. 
FREYRE, Gilberto. Interpretação do Brasil. São Paulo: Cia das Letras, 2001. FRASER, Nancy. Da redistribuição ao reconhecimento? Dilemas da justiça na era pós-socialista. In: SOUZA, Jessé (Org.). Democracia hoje: novos desafios para a teoria democrática hoje. Brasília: Editora Universidade de Brasília, 2001.

GIDDENS, Anthony. A Transformação da Intimidade. Sexualidade, amor e erotismo nas sociedades modernas. São Paulo: UNESP, 1993.

GOFFMANN, Erving. A representação do eu na vida cotidiana. Petrópolis: Vozes, 1989.

GUERRIERO, Silas. Novos movimentos religiosos. O quadro brasileiro. São Paulo, Paulinas, 2006.

HABERMAS, Jürgen. Entre naturalismo e religião: estudos filosóficos. Rio de Janeiro: Tempo Brasileiro, 2007.

HERVIEU-LÉGER, Daniele. O peregrino e o convertido - a religião em movimento. Petrópolis: Vozes, 2008.

HOMOFOBIA. Disponível em: www.cartacapital.com.br. Acesso em: 22 maio 2016.

LE GOFF, Jacques. O nascimento do purgatório. Lisboa: Editorial Estampa, 1995.

LEITE, Fábio Carvalho. Estado e religião. A liberdade religiosa no Brasil. Curitiba: Juruá, 2014.

LOREA, Roberto (Org.) Em defesa das liberdades laicas. Porto Alegre: Livraria do Advogado, 2008.

LOURO, Guacira Lopes. Gênero, sexualidade e educação: uma perspectiva pós-estruturalista. Rio de Janeiro: Vozes, 2007.

LUCKMANN, Thomas. A religião invisível. São Paulo: Olho d'água/ Loyola, 2014.

MACHADO, Maria das Dores Campos. Aborto e ativismo religioso nas eleições de 2010. Revista Brasileira de Ciências Política 7, 2012. p. 25-37.

. Religião e as assimetrias de gênero na América Latina. In: ORO, Ari Pedro (Org.). A latinidade da América Latina: enfoques sócio antropológicos. São Paulo: Aderaldo \& Rothschild, 2008. p. 241-64. 
MACHADO, Maria das Dores Campos; PICOLO, Fernanda Delvalhas. Religião e homossexualidade. Rio de Janeiro: Fundação Getúlio Vargas, 2011. MAGNO MALTA e a criação de império homossexual. Disponível em: www12.senado.gov.br. Acesso em: 10 jun. 2016.

MALAFAIA, Silas. Minhas experiências de vida. Rio de Janeiro: Editora Central Gospel, 2012.

MARTELLI, Stefano. A religião na sociedade pós-moderna: entre secularização e dessecularização. São Paulo: Paulinas, 1995.

MARTI, Gerardo; GANIEL, Gladys. The deconstructed church. Understanding emerging Christianity. Oxford: University Oxford Press, 2014.

MCLAREN, Peter. Multiculturalismo crítico. São Paulo: Cortez, Instituto Paulo Freire, 1997.

MORI, Maurizio. A moralidade do aborto: sacralidade da vida e o novo papel da mulher. Brasília: Editora UnB, 1997.

MUJICA, Jaris. Os grupos conservadores na América Latina. Transformações, crises, estratégias. In: JURKEWICZ, Regina Soares (Org.). Quem controla as mulheres? Direitos reprodutivos e fundamentalismos religiosos na América Latina. São Paulo: Católicas pelo Direito de Decidir, 2011.

NATIVIDADE, Marcelo Tavares. "Homossexualidade, gênero e cura em perspectivas pastorais evangélicas”. Revista Brasileira de Ciências Sociais. vol. 21, n. 61, São Paulo: EDUSC, 2006.

ORO, Ari Pedro. Avanço pentecostal e reação católica. Petrópolis: Vozes, 1996.

RIOS, Roger Raupp; GOLIN, C.; LEIVAS, Paulo Gilberto Cogo. Homossexualidade e direitos sexuais: reflexões a partir da decisão do STF. Porto Alegre: Sulina, 2011.

ROSADO-NUNES, Maria José Fontelas. Direitos, cidadania das mulheres e religião. Tempo Social (USP). v. 20, n. 2, p. 67-81, nov. 2008.

SAFFIOTI, Heleieth. Gênero, patriarcado, violência. São Paulo: Perseu Abramo, 2004.

SANTOS, Boaventura de Sousa. (Org.) Reconhecer para libertar: os caminhos do cosmopolitismo multicultural. Rio de Janeiro: Civilização Brasileira, 2003. 
2014.

. Se Deus fosse um ativista dos direitos humanos. São Paulo: Cortez,

SARMENTO, Daniel. Livres e iguais: estudos de direito constitucional. Rio de Janeiro: Lumen Juris, 2006.

SEMPRINI, Andréa. Multiculturalismo. Bauru: EDUSC, 1999.

SHELDON, Louis. P. A estratégia (The Agenda): o plano dos homossexuais para transformar a sociedade. Rio de Janeiro: Editora Central Gospel Ltda., 2012.

SORJ, Bernardo. A nova sociedade brasileira. Rio de Janeiro: Zahar, 2001.

TOURAINE, Alain. Um novo paradigma: para compreender o mundo de hoje. Petrópolis: Vozes, 2006.

VANEIGEM, Raoul. Nada é sagrado, tudo pode ser dito: reflexões sobre a liberdade de expressão. São Paulo: Parábola Editorial, 2004. 


\title{
Resumo:
}

A lógica que configura a composição do quadro doutrinário religioso conservador na contemporaneidade brasileira, supõe uma cartografia discursiva marcada pela fragmentação das subjetividades. A religiosidade conservadora se articula e amolda, em grande medida, com base em um discurso acusatório que deriva dessa sua capacidade de tocar, atingir, incorporar e reorientar alguns elementos presentes no universo simbólico de referência da população brasileira. O artigo pretende aprofundar a perspectiva dos direitos humanos, as questões inerentes às minorias e grupos vulneráveis, o preconceito suscitado pela violência simbólica e a retórica do preconceito alicerçado pela crítica pública com nuances fundamentalistas.

Palavras-chave: Grupos Conservadores; Intolerâncias; Sexualidades.

\begin{abstract}
:
The logic that sets up the composition of the framework doctrinal religious conservative on contemporary brazilian, assumes a new discursive mapping marked by the fragmentation of subjectivity. The conservative religious is organized and shaped, to a larger extent, upon an accusatory speech that derives from its capacity to touch, reach, incorporate and redirect some elements found in the symbolic universe of reference of the Brazilian population. This paper intends to deepen the perspective of human rights, the issues inherent to minorities and vulnerable groups, the prejudice raised by symbolic violence and the rhetoric of prejudice supported by public criticism with fundamentalist nuances.
\end{abstract}

Keywords: Conservative Groups; Intolerance; Sexualities. 